This is a so-called personal version (author's manuscript as accepted (18 $8^{\text {th }}$ June 2018) for publishing after the review process but prior to final layout and copyediting) of the article. This version of the publication may differ from the final published version. Researchers are kindly asked to use the official publication in references.

Citation: Vaara, E., Rantakari, A. and Holstein, J. Participation Research and Open Strategy in: R. Whittington, G. von Krogh and D. Seidl (eds.), Handbook of Open Strategy. Cambridge, UK: Cambridge University Press.

\title{
Participation Research and Open Strategy
}

\author{
Eero Vaara \\ Aalto University School of Business \\ Anniina Rantakari \\ University of Oulu Business School \\ Jeannie Holstein \\ Nottingham University Business School, UK
}

\begin{abstract}
In this chapter we focus on participation in open strategy. We examine how the issue of participation has been dealt with in previous strategy literature and elaborate on how research on open strategy can be linked with and advance this body of work. We identify three main views on participation in strategy research: participation as an inherent part of the strategy process, participation as enabled or constrained by practices, and participation as an issue of subjectivity. We then elaborate three distinctively different approaches to participation that might inform our understanding of inclusion in open strategy: open strategy as limited participation, open strategy as co-creation of strategies, and open strategy as 'deep engagement' defining the rules of the game. Based on these approaches, we discuss their implications on open strategy research and suggest a research agenda for future studies of participation in open strategy.
\end{abstract}

Keywords: participation, practice, process, subjectivity, power 


\section{Participation Research and Open Strategy}

\section{Introduction}

Recent studies have raised participation as one of the key issues of open strategy (Luedicke et al., 2017; Mack \& Szulanski, 2017). However, participation has a longer tradition in strategy research (Laine \& Vaara, 2015; Mantere \& Vaara, 2008) from which open strategy could learn from and contribute to. In this chapter, we review research on participation and discuss its implications for open strategy and vice versa.

Participation is a dynamic and multifaceted phenomenon the nature and effects of which are not easy to pin down. Participation can generate engagement and create commitment to strategy and similarly improve the quality of decision-making (Floyd \& Wooldridge, 2000). In contrast, limiting participation through secrecy and exclusion may result in ineffective implementation (Mintzberg, 1994), and from a critical perspective, even exacerbate organizational inequality (Knights \& Morgan, 1991; McCabe, 2010). However, participation can also slow down decision-making and constrain the strategy process (Collier et al., 2004; Anderson, 2004). Moreover, widespread participation can create expectations that are then not satisfied, particularly where the decision might be contrary to the advice given by participants (Kornberger and Clegg, 2011). Thus, studies on participation in strategy invite questions about its nature and limits, which should be taken seriously in research and practice.

The dynamics of participation can be seen as particularly relevant to research on open strategy for two reasons. First, next to transparency, inclusion is one of the defining characteristics of open strategy (Hautz et al., 2017; Whittington et al, 2011). Thus, participation is at the core of the concept of open strategy. Second, current research has identified broad questions which scholarship on open strategy might both learn from and contribute to. This is especially the case when the focus is on inclusion, defined as the range of people involved in making strategy (Quick and Feldman, 2011; Whittington et al., 2011). 
Scholars have elaborated on different approaches when studying participation in strategy-making, notably in terms of inclusion (Laine \& Vaara, 2007, 2015; Mantere \& Vaara, 2008). These range from traditional studies of top level strategy-making that tends to see participation as a non-issue, to studies of the strategy process, to the practices that enable or constrain participation in strategymaking, and to the consideration how participation and the subjectivities of the people involved are defined in discourse (Laine and Vaara, 2015). Nonetheless, there remain broad questions such as to who is included and how they are included; how this inclusion leading to participation is enabled or impeded through social practices, technologies and discursive resources; and how in relationships between participants shared meaning about inclusion may be developed or at times resisted.

Thus, in this chapter we review existing research on participation in strategy and examine how that can inform our understanding of participation in open strategy. We start by offering an overview of how previous strategy literature has dealt with participation. We then distinguish between three distinctively different approaches to participation that can inform our understanding of inclusion in open strategy: open strategy as limited participation, open strategy as co-creation of strategies, and open strategy as 'deep engagement' defining the rules of the game. We will then elaborate on these three approaches, their characteristics, and implications for research in this area. Finally, we will move on to discuss key theoretical and methodological issues and suggest a research agenda for future studies of participation in open strategy.

\section{An Overview of Participation in Strategy Research}

In this section, we offer an overview of how strategy research has dealt with the issue of participation. Traditionally strategy research has treated strategy-making as the activity of top management; participation has thus remained a non-issue in the mainstream literature (Laine and Vaara, 2015). This emphasis on top management decision-making can be traced to the military origins of the strategy discipline (Bracker, 1980; Mintzberg et al., 1986; Rumelt, Schendel and Teece, 1994), traceable to the Greek verb 'stratego' that means planning the destruction of one's enemies through the effective use of resources (Bracker, 1980: 219; Kanter, 1989). Thus, strategy 
formation has been typically views as purposeful planning by top managers, and the role of others has been to implement these strategies (e.g. Andrews, 1981). However, recent research in strategy process and practice research has offered alternatives views on strategy-making in general and participation in particular (e.g. Burgelman et al, 2018). We next distinguish between three main views on participation in strategy research: participation as an inherent part of the strategy process, participation as enabled or constrained by practices, and participation as an issue of subjectivity.

\section{Participation as part of strategy process}

In contrast to more conventional strategy research, strategy process research (Pettigrew, 1973, 1992; Mintzberg, 1978) has offered important insights into participation in strategy-making - even if not usually explicitly focusing on participation per se. These studies have concentrated on the processes through which strategy is practically formulated and enacted (Bourgeois, 1980), the sequence of events associated with strategy, its temporal nature, and how it evolves over time. This led to a pivotal change of focus, on emergent strategies (Bower, 1970; Mintzberg \& Waters, 1985) and on strategy as a pattern of multiple actions (Bower, 1970; Mintzberg, 1978). As a result, participation in strategy has been extended out of the boardroom and into the behavior of those involved in a strategy process. It is this wider participation that started to assume strategic importance, from the entrepreneurial potential of middle management and the initiatives shown in projects by experts such as engineers, to the skills of lower middle management needed in new projects and the work of upper middle management in conceptualizing the strategic impact of the projects (Burgelman, 1983, 1991, 1994).

One of the key contributions of the early strategy process studies has been an increasing interest in the participation of middle managers as strategic actors. In an early study, Wooldridge and Floyd (1990) focused on how middle management participation influenced corporate performance. They showed that decision-making by middle management and with it the successful integration of diverse ideas, could lead to superior strategy formulation. However, their analysis unexpectedly demonstrated that middle management did not necessarily show commitment to strategy, and 
moreover demonstrated the importance of maintaining a critical stance toward strategy proposals. Soon after, Floyd and Wooldridge $(1992,1996)$ continued on the topic of middle management's role by classifying the actions of middle management into roles linked to both top-down and bottom-up strategizing and to either the integration of ideas or their diversification. In their subsequent work, Wooldridge and Floyd (2017) have in turn concluded that in the complex social processes that underpin successful performance, participation from top-level managers and importantly middle managers distributed across the organization is required. Moreover, each are required to play integrative strategic roles, while only some of them need to perform divergent strategic roles.

Westley (2000) examined strategy conversations and elaborated on the antecedents and implications of inclusion around strategic issues. She elucidated how middle managers experience inclusion as motivating and energizing if they are allowed to dominate or at least co-determine some aspects of the conversation. Ketokivi and Castañer (2004) in turn considered the integrative process and effect of participation in in more detail. They showed that participation in strategic planning and subsequent communication of its results reduces the possibility that employees would engage in subgoal pursuit and cause an integration problem. They contend that reducing bias is likely to lead to greater integration and less diversification of goals and in this way to increase commitment to the strategic objectives. In another study, Andersen (2004) showed that the autonomous participation of middle managers, allowing them to take initiatives is linked to positive economic performance. However, this distributed decision-making authority can to be more efficient when the company also has a formal strategic planning process that integrates strategic actions. This supports the view that while participation is valuable, restriction on participation - inclusion that is in some way constrained - is more crucial to strategic performance. Moreover, there needs to be constraint because participation of middle management in strategic decision-making is both time-consuming and resource-demanding and as consequence can outweigh any subsequent positive performance.

Participation of middle managers is in any case constrained within any system of management control. Values, purpose, and direction of the organization communicated by top management within such a system can enhance the proactiveness of middle management 
(Marginson, 2002). Administrative control systems in turn affect the location of strategic initiative and inclusion; some managers are assigned to make strategies concrete, while others are held accountable for assuring the efficiency of current activity. In strategy-making, multiple key performance indicators nevertheless lead middle managers to favor some measures at the expense of others. A study by Currie and Procter (2005) confirmed part of the results of Marginson's study around manager proactivity and also found that ambiguity of role expectations among stakeholders, including top managers, does in fact prevent middle managers from enacting their strategic roles. However, they also pointed out that the training of middle managers contributes to development of active strategic leadership.

\section{Participation as enabled or constrained by strategic practices}

Relatedly, strategy-as-practice scholars (Vaara \& Whittington, 2012) offer a distinctive focus not on the process of strategy formulation and emergence, but on activities and practices through which strategy is practically formulated and enacted. From much of the work of practice-based strategy research (Golsorkhi et al., 2015; Jarzabkowski and Spee, 2009; Vaara and Whittington, 2012) not only has the participation of a broader range of actors in strategy-making has been considered (Mantere \& Vaara, 2008; Laine \& Vaara, 2007; Laine et al., 2015) but the modes of participation and nature of inclusion have also been explored (e.g. Balogun et al., 2014). This inclusion is not simply about who might be considered a strategy practitioner (and thereby included), but also specific practices enabling or constraining participation have been in the focus of analysis.

Just like in strategy process research, strategy-as-practice research has focused attention on the role of middle managers' sensemaking (Balogun and Johnson, 2003, 2004; Rouleau and Balogun, 2011). For example, Rouleau and Balogun (2011) have elucidated the importance of both middle management sensemaking and sensegiving. Furthermore, there have been some studies that have examined the role of external actors such as consultants, who are known to influence outcomes when they participate in for example strategy workshops (Hodgkinson et al., 2006) or strategic reorganization initiatives (Molloy and Whittington, 2005). However, such studies have been 
relatively few and there is opportunity to broaden research into participation of non-organizational or other internal actors (Dobusch et al., 2017; Jarzabkowski and Spee, 2009).

In addition, strategy-as-practice scholars have examined the practices of strategy-making and even if these studies have not often focused on participation per se, they inform us about the problems and challenges of inclusion in strategy-making. For instance, there is a body of research on strategy meetings and the social practices involved (Guérard and Seidl, 2015; Jarzabkowski and Seidl, 2008). Scholars have also focused on use of the material artifacts such as PowerPoint in strategy-making (Jarzabkowski and Spee, 2011; Kaplan, 2011: Dameron et al, 2015). From these studies we know that interaction which stimulates open discussion tends to promote participation, and further that inclusion can also be both enhanced (Holstein, Starkey and Wright, 2018; Abdallah and Langley, 2014) or derailed (Jarzabkowski et al., 2010) through a degree of ambiguity in communication.

\section{Participation as subjectivity and power}

Closely related to parts of strategy-as-practice research, scholars have also examined the role of subjectivity and power in strategy-making (Dameron and Torset, 2014; Kornberger and Clegg, 2012; Laine and Vaara, 2007; Mantere and Vaara, 2008; Samra-Frederics, 2005). This perspective has examined participation as the construction and reconstruction of subjectivities, i.e. how specific actors and not others are given rights to participate in and exercise influence in strategy-making (Dameron and Torset, 2014; Laine and Vaara, 2007). Participation in this perspective becomes a question of power in terms of who is included and who excluded from participating. All this depends on how strategy-making is socially and discursively constructed, which some studies have shown can provide ontological security as a sense of order and control for some, at the same time as marginalizing others (Samra-Fredericks, 2005).

For instance, Laine and Vaara (2007) studied how subjectivity is linked with the mobilization of strategy discourse, which was the case of top management launching a strategy process or middle managers working on their own strategies. Interestingly, they also showed how engineers could resist 
strategy work. In their study, Ezzamel and Willmott (2008) in turn demonstrated how specific organizational practices such as accounting, gain strategic significance, and how these practices influence on what is considered strategic. This is relevant for participation since specific strategic practices can define who in organizations can participate in strategy processes. In another relevant study, Kornberger and Clegg (2011) highlighted how the performative effects of strategizing mobilized the public and legitimized outcomes of the process while silencing other voices. In this way, studies of subjectivity have contributed to strategy research by advancing our understanding of participation in terms of strategy agency and power dynamics.

In one of the rare studies focusing explicitly on participation in strategy-making, Mantere and Vaara (2008) identified discourses that either impede or enable participation. The discourses impeding participation included "mystification" (obfuscation of organizational decisions), "disciplining" (use of disciplinary techniques to constrain action) and "technologization" (ways in which technology limit degrees of freedom), and those that promoted participation comprised "selfactualization" (the ability of people to define objectives for themselves in strategy processes), "dialogization" (integrating top down and bottom up approaches to strategizing) and "concretization" (establishing clear processes and practices in and through strategizing). Understanding how different discourses can either promote or hinder participation in the context of strategy-making can provide a nuanced understanding of the dynamics of openness in general and inclusion in particular, not least regarding its breadth and depth.

Despite these advances, there are many issues that are as of yet poorly understood in research on participation in strategy-making. In particular, although some studies have provided insights into the broader range of actors found in organizational strategy and strategy-making, most studies have been limited to middle managers, and the role of other organizational members such as lower-level employees or external actors has been less apparent. Moreover, despite advances in research on the practices of strategy-making, our understanding of the various methods and technologies allowing for participation are limited. Finally, even more critical studies have highlighted key issues in terms of subjectivity and power relations and there are many issues related to for example resistance that 
warrant specific attention in future research.

\section{Three Approaches to Participation in Open Strategy}

As our review shows, participation can be seen as one of the central dynamics in strategy-making. Importantly, open strategy has recently emerged as a particularly interesting phenomenon that has a great deal to offer to our understanding of participation in strategy-making (Burgelman et al., 2018; Seidl and Whittington, 2014). In fact, open strategy may be seen as the most novel and even radical form of participation that may include 'extreme inclusion' (Luedicke et al., 2017; Mack and Szulanski, 2017; Whittington, 2011). However, conceptual diversity and even ambiguity prevail as to what 'openness' and 'inclusion' may mean and how they can be theorized and empirically examined in strategy research in general and in open strategy research in particular.

We next elaborate on how we can advance understanding of participation in open strategy. Based on our review of prior research we outline three approaches to participation in open strategy: open strategy as limited participation, open strategy as co-creation of strategies, and open strategy as 'deep engagement' defining the rules of the game. The key idea is to offer an organizing framework that elucidates distinctively different ways in which open strategy can be understood and what it entails in terms of the nature of participation, control and agency, the dynamics of strategy-making, and the problems and challenges encountered. Table 1 below offers a summary of the key characteristics and the key issues involved.

Insert Table 1 about here

\section{Open strategy as limited participation}

Although the term open strategy implies widespread transparency and inclusion in strategy-making, real-life examples and practices mostly tell a story of more limited participation. That is, oftentimes open strategy may involve transparency and inclusion in specific parts of the strategy process but not others. Moreover, the various tools and technologies that have made open strategy possible often focus on specific aspects of strategy-making - for which they have been designed. For instance, for quite some time organizations have been able to gather information such as 'weak signals' and 
generate new ideas by approaching stakeholders with IT solutions ranging from new types of survey to brainstorming online. There are also various kinds of technological solutions that allow for very open collaboration in the implementation of strategic ideas and initiatives. Thus, participation is enabled but also constrained by the methods or technologies available. For example, a survey or even brainstorming on line is set up with preconditions, who can participate and by when, and also less obviously by assumptions about the technical competence of participants, a long-standing constraint on participation (Dachler \& Wilpert, 1978).

In this approach, the strategy process is typically controlled by top management, or middle managers acting as 'proxy' for this control. There may be participation that allows for idea generation, voicing of concerns, or influence on the implementation of strategic ideas and initiatives, but this participation is often a consultative one. Thus, the actual formulation of strategy statements, the crafting of the strategy documents, and the key decisions and choices tend to be in the hands of top management as 'strategists.' Thus, this approach has its challenges. For instance, participation may look like "window-dressing" or "open-washing" that may not have a significant effect on strategy-making. Moreover, the participants may experience their role as limited or even "ceremonial" - especially if their ideas and views are not visible in the formal strategy documents or influential in terms of the decisions and actions made.

\section{Open strategy as co-creation of strategies}

Open strategy can also imply a more fundamental reorientation in strategy-making. That is, rather than limiting participation to specific parts of the strategy process, strategy-making can be based on widespread participation in the co-creation of strategies. Although not often used in strategy-making, the idea is exemplified in co-creating organizational strategies as wiki pages (Dobusch et al, 2017). Thus, anyone in a specific organizational setting may be invited to participate in strategy-making with an opportunity to have an impact on the outcome. Unlike more limited participation, the cocreation of strategies is based on an understanding that participation is not only about providing information or ideas but having a 'real' impact on the organization's strategy. 
In this approach, strategies are co-constructed by top managers and others alike with a focus on inclusion and transparency, but there is still someone - typically top management - orchestrating the process to determine the rules of the game in terms of the practices of the strategy process. The key element here that distinguishes co-creation from limited participation is the intent to open up the strategy process to a greater degree and a less prescribed or constrained relationship to organizational control, within either the open strategy initiative or the organization as a whole. This kind of openness does not mean the absence of rules or prescribed procedures (Dobusch et al., 2017) and thus the actual forms of participation are enabled or constrained by specific methods or technologies - the choice of which is typically in the hands of the key decision-makers in organizations.

Organizing such co-creation of strategies is not easy and it may very well be that many attempts still do not quite live up to the ideals of genuine co-creation or equality of participation. In addition, the actual orchestration of such processes could mean an escalating departure from the initial principles. There may be limitations in how co-creation can be organized in real time for instance, or how different voices can participate equally. Indeed, the rules that determine openness and closure play a key role in the co-creation of strategies. For example Dobusch et al (2017) investigated the challenges of opening up strategy-making by looking at an extreme case of Wikimedia, to understand the involvement of external actors in organizational strategizing. They found that there are limits to participation; for example in terms of who is allowed to vote for the administrators or who have the rights to delete content on Wikimedia.

Furthermore, it may be that strategy processes specifically designed as following the principles of open strategy may be challenged by other forms of decision-making in the organizations; for instance, issues that may be seen as particularly sensitive or requiring secrecy may not be dealt with in the open strategy forums at all due to the risk that competitors may get hold of strategic information (Appleyard and Chesbrough, 2017; Hautz et al., 2017). Moreover, people may not become committed to the new practices of open strategy, which may undermine both the effectiveness and legitimacy of open strategy work. 


\section{Open strategy as 'deep engagement' redefining the rules of the game}

The third approach to open strategy that we outline involves deep engagement beyond the cocreation of strategies. This view implies that the actors - not only top or middle management together not only work on the strategies but also define and thereby redefine the ways in which strategy processes are organized. Thus, this extreme type of participation means defining the rules of the game in a process that is not predetermined or controlled by top management - or any other actor. This may even result in an entire different 'game' being played. This approach is not limited to specific forms or practices of strategy-making, nor is it pre-determined by specific methods or technologies.

In this view, participation is in principle widespread and can generate novel ideas, often in an unanticipated manner. Thus, the organization of strategy work happens alongside widespread participation, which also resonates with the ideas of open innovation and tends to create strong commitment. This approach to participation is like a social movement that emerges in a network society - empowered by the opportunities of virtual technology and social media, for example the Wiki tool is central to inclusion and wide participation at Wikimedia, precisely because it provides a collaborative, IT-mediated workspace of interlinked webpages (Dobusch et al., 2017) making contribution seamless and almost instant.

This approach may also be best understood as a utopia or an idealistic form of open strategymaking - reflecting the values of equality and unlimited engagement in a virtual and global society. Thus, most attempts to enact these principles probably lead to limitations and make such efforts resemble our second approach - open strategy as co-creation of strategies. This organization of "extreme inclusion" is indeed challenging for organization (Hautz et al., 2017). On the one hand, extreme inclusion can include a risk of "anarchy" if and when people are not able to reach some kind of co-orientation or shared views - not to speak of full agreement. Indeed, this extreme form of inclusion and participation can even lead to a 'tyranny of structuralessness' (Freeman, 1973/4) where participation for certain groups may even be reduced (Dobusch et al., 2017), since a lack of structure may replicate power effects in other ways. However, it might also be important to acknowledge that 
increased inclusion is not always that welcomed by potential participants since it may bring more expectations and additional tasks that require extra time and effort on top of everything else (Hautz et al., 2017). Hence, unlimited engagement may then sow the seeds of its own failure or limitation. Further, full equality is rarely reachable since specific actors tend to gain control and have more power than others - depending on how strategy work then gets to be organized and on whose terms.

However, we argue that it is very important to point to this third approach that challenges the usual assumptions about specific actors - typically top managers - in charge of the organization or orchestration of strategy work. By highlighting this third approach, we also come closer to the fundamental issues of subjectivity and power that more critical researchers have started to highlight in strategy-making (Ezzamel and Willmott, 2008; Laine and Vaara, 2007). Open strategy, like other forms of strategy is not neutral. Indeed, open strategy as it is typically thought of or practiced also includes assumptions and power relations that have a significant impact on participation and inclusion - with implications on subjectivity and power relations in terms of how organizational members at different organizational levels can position themselves into strategy and its practices (Laine et al., 2015). It is these practices and assumptions that are in our view the most interesting ones to be examined in future research on open strategy, not least because of the potentially uncontainable nature of open strategy.

\section{Key Issues for Future Research}

We have argued that there are three distinctively different approaches to participation in open strategy: limited participation, co-creation of strategy and deep engagement. However, we acknowledge that the boundaries between the three approaches are merely analytical distinctions and moreover can become increasingly blurred in the practice of open strategy. However, either in design or through practice, there are some common issues to each. It is these issues we wish to highlight for future research on participation in open strategy. They include authenticity vs. ceremoniality, technology as an enabler and constraint, the relation between openness and closure in participation, power and control, and the influences of socio-cultural practices on open strategy. 


\section{Authenticity vs. ceremoniality of participation}

Open strategy involves new ways of developing organizational strategies, but it can also be understood as a performance (Kornberger and Clegg, 2011) or even ritual (Johnson et al., 2010). We have already acknowledged that participation in strategy-making could be seen as "windowdressing" or "open-washing" in the case of limited participation. In other words, this can mean that even though participation is explicitly talked about as having a central role in the organization, inclusion may be limited in scope and authenticity. In this way, participation may become a performance or game along with designated members of the organization have to play, but actually the rules (and thereby the objective) of game have already been esoterically decided.

Ceremoniality or performance for its own sake, can have a long-standing impact on any future inclusion or engagement in open strategy. In addition, it can also diminish the efforts of top management to both communicate and build shared commitment in terms of shared strategy objectives. Moreover, ceremoniality in participation can deflect the enactment of strategies. In contrast, authentic participation might provide a fillip to inclusion, engagement, commitment and effectiveness. The challenge for future research is to examine how and to what extent open strategy as a performance may involve ritualization and ceremoniality - and the implications thereof.

\section{Technology as an enabler or constraint of participation}

Technology and particularly social software technologies are key enablers of open strategy (Whittington, 2014). This is not to say that conventional practices that encourage wide inclusion such as large-scale meetings (Mack and Szulanski, 2011) are irrelevant in open strategy, but rather technology enables the scale and scope of inclusion to be manifestly different. The platforms provided by technology allow people to connect from virtually anywhere in the world in virtual spaces such as social media, instant messaging platforms and video conferencing. Open strategy practices such as 'jamming,' an online collaboration event, where participants post ideas and vote on solutions and widely used in organizations such as IBM, are technology enabled. Thus, using such technology can make strategy formation less resource intensive and quicker, as well as more 
extensive, reaching though hierarchical layers (Stiegler et al., 2012), operating in real time, with instant feedback loops, unconstrained by any sequencing. Thus, technology can add scale to open strategy and enable the participation of a/the crowd in open strategy. However, technology can also be used to artificially constrain inclusion, channeling and reinforcing bias through a series of algorithms, in a similar way to that which has been labelled against Cambridge Analytical using Facebook data (Cadwalldar, 2018). Technology can therefore add scope to inclusion in open strategy, but equally technology can generate a loss of scope, unknowingly or unwittingly for the participants.

Such crowdsourcing is perceived as intrinsically democratizing. However, participation is not necessarily equal, and a virtual space does not necessarily eliminate hierarchies. Further, this virtual space is moderated in some form, and the technology that promotes inclusion also serves moderation, and thereby places limits of inclusion both in quantity and type. Moreover, how limits are set is not

necessarily transparent. Technology can be used to constrain transparency more easily than in conventional strategic episodes where setting ground rules for participation are intrinsic to eliciting that participation (Hendry and Seidl, 2003). In other words, technology can appear to enable inclusion without necessarily doing so. Thus, future research needs to consider the enabling and constraining effects of technology on participation and inclusion in open strategy, alongside questions of how demarcation between idea generation and decision-making can be sustained in the case of highly digitally mediated inclusion.

\section{Openness and closure in participation}

As shown in our review, participation involves a number of processes and practices - and the orchestration of strategy work. This orchestration requires specific platforms or arenas that may be opened or closed to allow for engagement or participation, and these processes of opening and closing as well as the social and organizational practices involved require attention in future research on open strategy (Dobusch et al., 2017). In particular, certain forms of closure may be necessary to achieve desired open qualities in strategy-making. Dobusch et al. (2017) noted that any attempt to 
achieve greater openness requires at least some degree of closure of the overall procedures (e.g. specifying who is allowed to participate and how) to enable certain open qualities (e.g. content creation) (Dobusch et al., 2017b). This is a crucial issue especially in terms of participation since it allows the elaboration of where and when participation begins and ends, how closure is best determined and realized, and under what circumstances optimal commitment in that participation occurs over time. These are important questions to be explored in future research where one could also highlight differences between the three different approaches to participation outlined in our framework.

\section{Power and control in participation}

Both power and control are key issues in open strategy as top management is more often than not seen as the key actor in strategy-making (Hardy and Thomas, 2014). Existing studies have examined top management's role from a critical perspective and emphasized the question of organizational inequality in terms of lack of inclusion (Knights and Morgan, 1991; McCabe, 2010). However, participation may also be seen as a form of control in and through which organizational members or other actors are drawn into organizational decision-making that is largely orchestrated by top management. This goes back to the historical tenets of strategic management that have stressed the role of top management in providing goals, directions, guidelines, structures and control systems to other managers (Burgelman, 1983). Moreover, this can lead to a situation where participation is taken into account, but it is then considered instrumentally as a means to achieve strategic goals. Thus, it is interesting and important to ponder whether open strategy may be used as an instrument of control to align lower level organizational practices with the goals and objectives crafted by top management. In addition, there is a need to reflect upon whether organizational members can be 'seduced' to participate in strategic decision-making even if that would not be in their interest (see also Allard-Poési, 2015). Furthermore, we may ask whether organizational members can be forced to participate - as in 'participation by command' (Eriksson \& Lehtimäki, 1998, 2001) - and on which terms. 
The issue of disagreement warrants special attention in future research on open strategy. When approached from the perspective of power and control, the space created for participation is unlikely to be a neutral one, even if designed as such. At some point there is likely to be disagreement, and such disagreements can even be integral to the creativity and diversity of an open strategy process. However, disagreement between participants can also potentially destabilize the whole process, and it may be hard to contain. Similarly, the nature of participation and how it is organized, can itself create discontent among participants. If there is no productive outlet for this discontent the implications could be severe. How discontent in participation is managed or filtered out, as part an ongoing process is therefore of concern in future research. Moreover, disagreement may also lead to resistance (Rantakari and Vaara, 2016), and exploring the various modes of resistance and their implications on open strategy is another important issue that requires specific attention in future research. Finally, new processes and practices of open strategy may also involve shifts power positions and relations within organizations; for instance, technological competence may imply new authority and power vis-à-vis more conventional power related to organizational hierarchy.

\section{The influence of socio-cultural practices on participation}

Embedded within the open strategy framework is the assumption or even prescription that participation is a good thing. This is because it has some shared intellectual ground with innovation, where a belief in the diversity of opinions and the engagement of the many, is central. However, the practices of inclusion, even those subsequently labelled as open strategy are culturally steeped in wider social practices. Thus, the way we typically see open strategy tends to reflect western values and practices, whereas the views might be very different in other cultural and societal contexts. In addition, there are differences between Anglo-American or European modes of corporate governance and employee rights that can have a major impact on how specific methods of open strategy would work in particular contexts (see Kornberger et al, 2017, for a rare comparison of strategy-making practices in Sydney and Vienna). Furthermore, societies that are based on consensus decision- 
making rather than participatory democracy would necessarily question whether each voice is equal but would also have a tradition of spending more time in the process of consultation, to reach a consensus rather than a majority agreement or a representative position. The cultural context, specifically a democratic tradition in the macro, meso or micro setting, and the relationship to participation and inclusion is of future research interest.

Similarly, there are other conditions that have not yet gained much attention in research on participation. These conditions can be related for example to ethnicity, gender, and different backgrounds that have an impact on how we define what participation can mean. These conditions tend to produce specific assumptions about the nature of strategy-making and the role of participation in it. Thus, we should be conscious about the broader underlying assumptions related to strategy-making among practitioners but also focus attention on the assumptions that we as strategy scholars may reproduce.

\section{Conclusion}

Open strategy involves inclusion and transparency in strategy-making within and outside the organization (Hautz et al., 2017; Whittington et al., 2011). In particular, inclusion implies a need to involve and engage a number of stakeholders, and thus open strategy holds great promise in terms of advancing participation in strategy-making. Nevertheless, this promise has not as of yet been fully realized, and this is why there is a need to link this new stream of research to the existing bodies of knowledge in strategy process and practice research - as well as to go beyond strategy research to be able to advance our understanding of participation in a theoretically grounded manner. Thus, drawing on prior research on participation, we have outlined three distinctively different approaches to participation in open strategy: open strategy as limited participation, open strategy as co-creation of strategies, and open strategy as 'deep engagement' defining the rules of the game. We have also highlighted a number of issues that warrant attention in future research on participation in open strategy: authenticity vs. ceremoniality, technology as an enabler and constraint, openness and 
closure in participation, power and control, and the influences of socio-cultural practices on open strategy.

We hope that this chapter inspires not only scholars but also practitioners to see both the huge potential but also the challenges in participation in open strategy. Open strategy offers an umbrella term and a set of practices that can be used very effectively to promote participation in strategymaking - in ways that could not be imagined just a few years ago. Nevertheless, there is no single approach to open strategy and it is important to understand that the conceptions and applications of open strategy may be very different in different contexts. Thus, there is a need for both theoretical and empirical work to elucidate what the processes and practices of open strategy imply in terms of participation. This is an exciting challenge for researchers and practitioners alike. 


\section{References}

Abdallah, C., \& Langley, A. (2014). The double edge of ambiguity in strategic planning. Journal of Management Studies, 51(2), 235-264.

Allard-Poési, F. (2015). A Foucauldian perspective on strategic practice: strategy as the art of (un) folding. In Golsorkhi D, Rouleau L, Seidl D \& Vaara E (eds). The Cambridge Handbook of Strategyas-Practice, 234-248. Cambridge: Cambridge University Press.

Andersen, T. J. (2004). Integrating decentralized strategy making and strategic planning processes in dynamic environments. Journal of Management Studies, 41(8), 1271-1299.

Andrews, K. R. (1987). The Concept of Corporate. Strategy, $3^{\text {rd }}$ ed. Homewood, IL: Irwin.

Balogun, J., \& Johnson, G. (2004). Organizational restructuring and middle managers sensemaking. Academy of Management Journal, 47(4), 523-549.

Balogun, J., \& Johnson, G. (2005). From intended strategies to unintended outcomes: The impact of change recipient sensemaking. Organization Studies, 26(11), 1573 - 1601.

Balogun, J., Jacobs, C., Jarzabkowski, P., Mantere, S., \& Vaara, E. (2014). Placing strategy discourse in context: Sociomateriality, sensemaking, and power. Journal of Management Studies, 51(2), 175-201.

Bourgeois III, L. J. (1980). Strategy and environment: A conceptual integration. Academy of management Review, 5(1), 25-39.

Bower, J. L. (1970). Managing the resource allocation process. Boston: Harvard University Press.

Bracker, J. (1980). The historical development of the strategic management concept. Academy of Management Review, 5(2), 219-224.

Burgelman, R. A. (1983). A model of the interaction of strategic behavior, corporate context, and the concept of strategy. Academy of Management Review, 8(1), 61-70.

Burgelman, R. A. (1991). Intraorganizational ecology of strategy making and organizational adaptation: Theory and field research. Organization Science, 2(3), 239-262.

Burgelman, R. A. (1994). Fading memories: A process theory of strategic business exit in dynamic environments, Administrative Science Quarterly, 39(1), 24-56.

Burgelman, R. A., Floyd, S.W., Laamanen, T., Mantere, S., Vaara, E., \& Whittington, R. (2018). Strategy processes and pratices: Dialogues and intersections. Strategic Management Journal, 39(3), 531-558.

Cadwalladr, C., \& Graham-Harrison, E. (2018). How Cambridge Analytica turned Facebook 'likes' into a lucrative political tool. The Guardian. 17 March 2018. Available from https://www.theguardian.com/technology/2018/mar/17/facebook-cambridge-analytica-kogan-dataalgorithm.

Collier, N., Fishwick, F., \& Floyd, S. W. (2004). Managerial involvement and perceptions of strategy process. Long Range Planning, 37(1), 67-83. 
Currie, G., \& Procter, S. J. (2005). The antecedents of middle managers' strategic contribution: The case of a professional bureaucracy. Journal of management studies, 42(7), 1325-1356.

Dachler, H. P., \& Wilpert, B. (1978). Conceptual dimensions and boundaries of participation in organizations: A critical evaluation. Administrative Science Quarterly, 23(1), 1-39.

Dameron, S., \& Torset, C. (2014). The discursive construction of strategists' subjectivities: Towards a paradox lens on strategy. Journal of Management Studies, 51(2), 291-319.

Dameron, S., Lê, J. K., \& LeBaron, C. (2015). Materializing strategy and strategizing material: Why matter matters. British Journal of Management, 26(S1).

Dobusch, L., Dobusch, L., \& Müller-Seitz, G. (2017). Closing for the benefit of opening: The case of Wikimedia's open strategy process. Organization Studies, forthcoming. Available online at http://journals.sagepub.com/doi/abs/10.1177/0170840617736930

Eriksson, P., \& Lehtimäki, H. (2001). Strategy rhetoric in city management: How the presumptions of classic strategic management live on? Scandinavian Journal of Management, 17(2), 201-223.

Ezzamel, M. \& Willmott, H. (2008). Strategy as Discourse in a Global Retailer: A Supplement to Rationalist and Interpretive Accounts. Organization Studies, 29(2), 191- 217.

Felin, T., \& Foss, N.J. (2005). Strategic organization: A field in search of micro-foundations. Strategic Organization, 3, 441-455.

Felin, T., Foss, N.J., Heimericks, K.H. \& Madsen, T.L. (2012). Microfoundations of routines and capabilities. Journal of Management Studies, 49 (8), 1351-1374 .

Floyd, S. W., \& Wooldridge, B. (1992). Middle management involvement in strategy and its association with strategic type: A research note. Strategic Management Journal, 13, 153-167.

Floyd, S. W., \& Wooldridge, B. (1996). The strategic middle manager: How to create and sustain competitive advantage. San Francisco: Jossey-Bass.

Floyd, S. W., \& Wooldridge, B. (2000). Building Strategy from the Middle: Reconceptualizing Strategy Process. London: Sage.

Freeman, J. (1972). The tyranny of structurelessness. Berkeley Journal of Sociology, 17, 151-164.

Gavetti, G. (2005). Cognition and Hierarchy: Rethinking the Microfoundations of Capabilities' Development. Organization Science, 16(6), 599-617.

Golsorkhi, D., Rouleau L., Seidl, D., \& Vaara, E. (2015). Cambridge Handbook of Strategy as Practice. Cambridge: Cambridge University Press.

Hardy, C., \& Thomas, R. (2014). Strategy, discourse and practice: The intensification of power. Journal of Management Studies, 51(2), 320-348.

Hautz, J., Seidl, D., \& Whittington, R. (2017). Open strategy: Dimensions, dilemmas, dynamics. Long Range Planning, 50(3), 298-309.

Hodgkinson, G. P., Whittington, R., Johnson, G., \& Schwarz, M. (2006). The role of strategy 
workshops in strategy development processes: Formality, communication, co-ordination and inclusion. Long Range Planning, 39(5), 479-496.

Holstein, J., Starkey, K., \& Wright, M. (2018). Strategy and narrative in higher education. Strategic Organization, 16(1), 61-91.

Jarzabkowski, P., \& Seidl, D. (2008). The role of meetings in the social practice of strategy. Organization Studies, 29(11), 1391-1426.

Jarzabkowski, P. \& Spee, A.P. (2009). Strategy-as-Practice: A review and future directions for the field. International Journal of Management Reviews, 11(1), 69-95

Jarzabkowski, P., Sillince J.A.A., \& Shaw, D. (2010). Strategic ambiguity as a rhetorical resource for enabling multiple strategic goals. Human Relations, 63(2), 219-248.

Johnson, G., Prashantham, S., Floyd, S. W., \& Bourque, N. (2010). The ritualization of strategy workshops. Organization Studies, 31(12), 1589-1618.

Kanter, R. M. (1989). The new managerial work. Harvard Business Review, 67(6), 85-92.

Kaplan, S. (2011). Strategy and PowerPoint: An inquiry into the epistemic culture and machinery of strategy-making. Organization Science, 22(2), 320-346.

Ketokivi, M. \& Castañer, X. (2004). Strategic planning as an integrative device. Administrative Science Quarterly, 49(3), 337-365.

Knights, D. \& Morgan, G. (1991). Corporate Strategy, Organizations, and Subjectivity: A Critique. Organization Studies, 12(2), 251-273.

Kornberger, M. \& Clegg, S. (2011). Strategy as performative practice: The case of Sydney 2030. Strategic Organization, 9(2): 136-162.

Kornberger, M., Meyer, R. E., Brandtner, C., \& Höllerer, M. A. (2017). When bureaucracy meets the crowd: Studying "open government" in the Vienna City administration. Organization Studies, 38(2), 179-200.

Kownatzki, M., Walter, J., Floyd, S. W., \& Lechner, C. (2013). Corporate control and the speed of strategic business unit decision making. Academy of Management Journal, 56(5), 1295-1324.

Laine, P. M. \& Vaara, E. (2007). Struggling over subjectivity: A discursive analysis of strategic development in an engineering group. Human Relations, 59(5), 611-636.

Laine, P-M., and Vaara, E. (2015). Participation in strategy work. In D. Golsorkhi , L. Rouleau, D. Seidl \& E. Vaara (eds.). Cambridge Handbook of Strategy as Practice $2^{\text {nd }}$ ed., 616-631. Cambridge: Cambridge University Press.

Laine, P.-M., Meriläinen, S., Tienari, J. and Vaara, E. 2016. Mastery, submission, and subversion: On the performative construction of strategist identity. Organization, 23(4): 505-524.

Luedicke, M. K., Husemann, K. C., Furnari, S., \& Ladstaetter, F. (2017). Radically open strategizing: how the premium cola collective takes open strategy to the extreme. Long Range Planning, 50(3), 371-384. 
Mack, D. Z., \& Szulanski, G. (2017). Opening up: how centralization affects participation and inclusion in strategy making. Long Range Planning, 50(3), 385-396.

Mantere, S., \& Vaara, E. (2008). On the problem of participation in strategy: A critical discursive perspective. Organization Science, 19(2), 341-358.

Marginson, D. E. W. (2002). Management control systems and their effects on strategy formation at middle-management levels: Evidence from a UK Organization. Strategic Management Journal, 23(11), 1019-1031.

McCabe, D. (2010). Strategy-as-Power: Ambiguity, Contradiction and the Exercise of Power in a UK Building Society. Organization, 17(2), 151-175.

Mintzberg, H. (1978). Patterns in strategy formation. Management Science, 24(9), 934-948.

Mintzberg, H. (1994). The rise and fall of strategic planning. Harvard Business Review, 72(1), 107114.

Mintzberg, H., \& Waters, J. A. (1985). Of strategies, deliberate and emergent. Strategic Management Journal, 6(3), 257-272.

Mintzberg, H., Brunet, J. P., \& Waters, J. A. (1986). Does planning impede strategic thinking? Tracking the strategies of Air Canada from 1937 to 1976. Advances in Strategic Management, 4(1).

Molloy, E \& Whittington, R. (2005). Organising organising: The practice inside the process. Advances in Strategic Management, 22, 491-515.

Pettigrew, A.M. (1973). The Politics of Organizational Decision-Making. London: Tavistock Publications.

Pettigrew, A. M. (1992). The character and significance of strategy process research. Strategic Management Journal 13(1), 5-16.

Powell, T. C., Lovallo, D., \& Fox, C. R. (2011). Behavioral strategy. Strategic Management Journal, 32(13), 1369-1386.

Quick, K. S., \& Feldman, M. S. (2011). Distinguishing participation and inclusion. Journal of Planning Education and Research, 31(3), 272-290.

Rantakari, A. \& Vaara, E. 2017. Narratives and processuality. In A. Langley \& H. Tsoukas (eds.). Sage Handbook of Process Organization Studies, 271-285. London: Sage.

Rouleau, L., \& Balogun, J. (2011). Middle managers, strategic sensemaking, and discursive competence. Journal of Management Studies, 48(5), 953-983.

Rumelt, R. P., Schendel, D. E., \& Teece, D. J. (1994). Fundamental issues in strategy: A research agenda. Boston, MA: Harvard Business School Press.

Samra-Fredericks, D. (2005). Strategic practice, "discourse" and the everyday interactional constitution of "power effects. Organization, 12(6), 803-841.

Seidl, D. \& Guérard, S. (2015). Meetings and workshops as strategy practices. In D. Golsorkhi, L. Rouleau, D. Seidl (eds). The Cambridge Handbook of Strategy as Practice, 564-581. Cambridge: 
Cambridge University Press.

Seidl, D., \& Whittington, R. (2014). Enlarging the strategy-as-practice research agenda: Towards taller and flatter ontologies. Organization Studies, 35(10), 1407-1421.

Spee, A. P., \& Jarzabkowski, P. (2011). Strategic planning as communicative process. Organization Studies, 32(9), 1217-1245.

Stieger, D., Matzler, K., Chatterjee, S., \& Ladstätter-Fussenegger, F. (2012). Democratizing strategy: How crowdsourcing can be used for strategy dialogues. California Management Review, 54(4), 1-26.

Vaara, E., \& Whittington, R. (2012). Strategy-as-practice: Taking social practices seriously. Academy of Management Annals, 6(1), 285-336.

Westley, F. R. (1990). Middle managers and strategy: Microdynamics of inclusion. Strategic Management Journal, 11(5), 337-351.

Whittington, R. (2014). Information systems strategy and strategy-as-practice: a joint agenda. The Journal of Strategic Information Systems, 23(1), 87-91.

Whittington, R., Cailluet, L., \& Yakis-Douglas, B. (2011). Opening strategy: Evolution of a precarious profession. British Journal of Management, 22(3), 531-544.

Wooldridge, B., \& Floyd, S. W. (1990). The strategy process, middle management involvement, and organizational performance. Strategic Management Journal, 11(3), 231-241.

Wooldridge, B., \& Floyd, S.W. (2017). Some middle managers are more influential than others: an approach for identifying strategic influence. In S.W. Floyd \& B. Wooldridge (eds.), Handbook of Middle Management Strategy Process Research, 56-77. Cheltenham: Edward Elgar. 


\begin{tabular}{|c|c|c|c|c|c|c|}
\hline & $\begin{array}{l}\text { Part in strategy } \\
\text { process }\end{array}$ & $\begin{array}{ll}\text { Nature } & \text { of } \\
\text { participation } & \end{array}$ & $\begin{array}{l}\text { Nature } \\
\text { inclusion }\end{array}$ & Control/agency & $\begin{array}{l}\text { Implications on } \\
\text { strategy-making }\end{array}$ & Problems/challenges \\
\hline $\begin{array}{l}\text { Open strategy as } \\
\text { limited } \\
\text { participation }\end{array}$ & 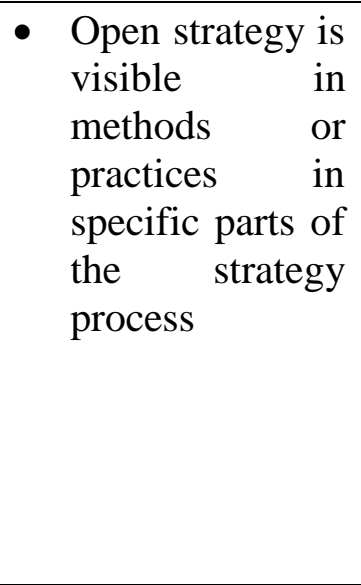 & $\begin{array}{l}\text { Participation } \\
\text { as enabled or } \\
\text { constrained by } \\
\text { the methods or } \\
\text { technologies } \\
\text { available }\end{array}$ & 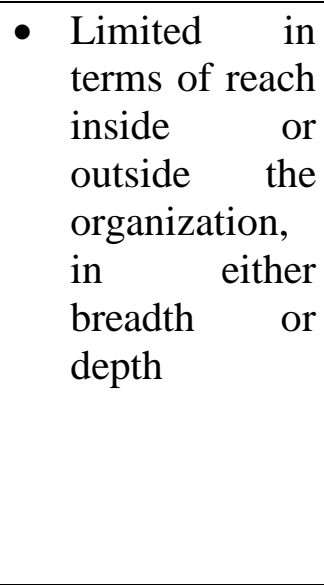 & $\begin{array}{l}\text { - Top management } \\
\text { typically in } \\
\text { charge of the } \\
\text { strategy process } \\
\text { - Participation of } \\
\text { others is limited } \\
\text { to specifics part } \\
\text { of the strategy } \\
\text { process }\end{array}$ & 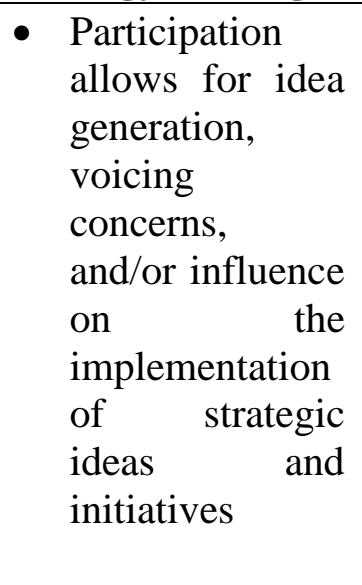 & 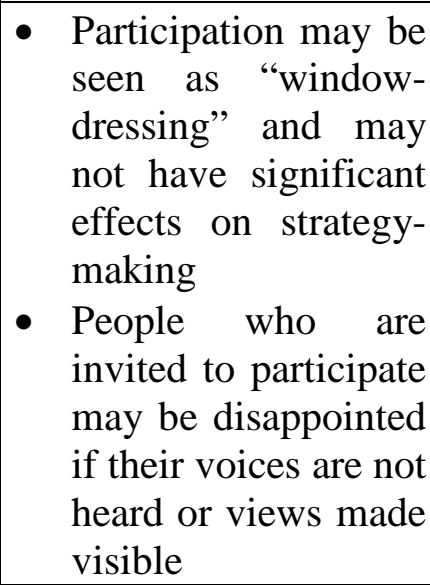 \\
\hline $\begin{array}{l}\text { Open strategy as } \\
\text { co-creation of } \\
\text { strategies }\end{array}$ & $\begin{array}{l}\text { - The strategy } \\
\text { process is } \\
\text { characteristicall } \\
\text { y designed to } \\
\text { allow for } \\
\text { widespread } \\
\text { participation in } \\
\text { terms of co- } \\
\text { creation of } \\
\text { strategies, with } \\
\text { a defined payoff }\end{array}$ & $\begin{array}{l}\text { - } \text { Participation is } \\
\text { enabled or } \\
\text { constrained by } \\
\text { specific } \\
\text { methods or } \\
\text { technologies }\end{array}$ & 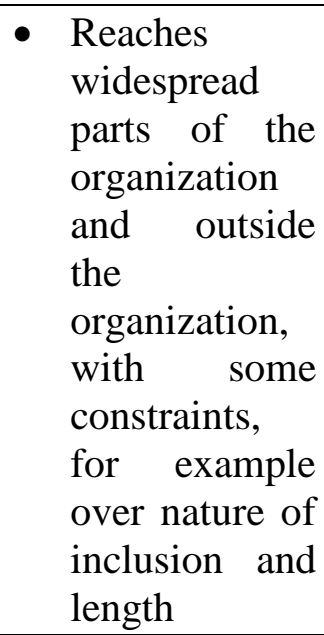 & 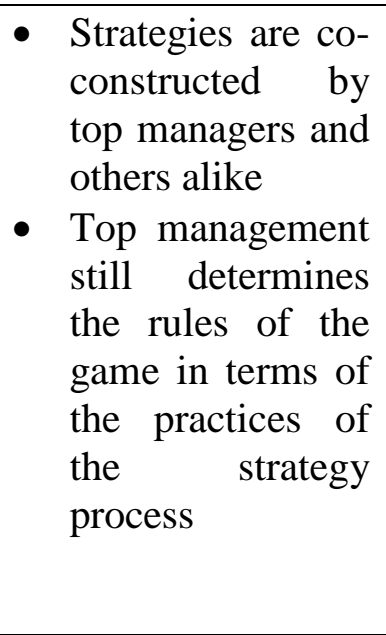 & 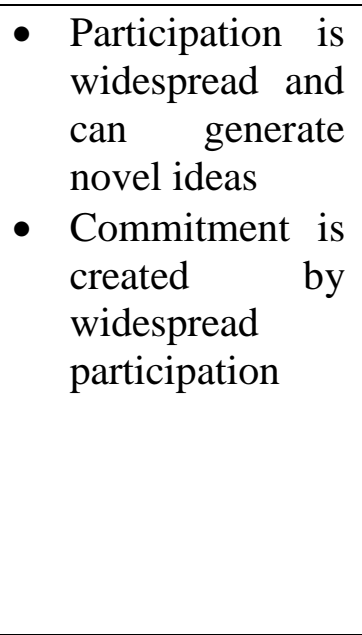 & 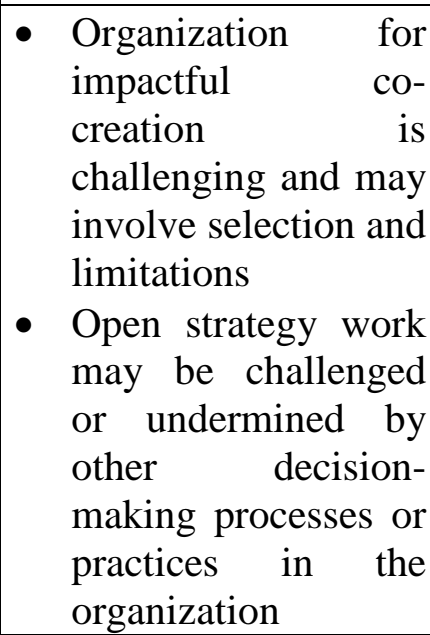 \\
\hline $\begin{array}{l}\text { Open strategy as } \\
\text { "deep } \\
\text { engagement" } \\
\text { defining the } \\
\text { rules of the } \\
\text { game }\end{array}$ & $\begin{array}{l}\text { - The actors } \\
\text { together define } \\
\text { the parameters } \\
\text { or "rules of the } \\
\text { game" of the } \\
\text { strategy } \\
\text { process, with no }\end{array}$ & $\begin{array}{l}\text { - Participation is } \\
\text { not pre- } \\
\text { determined by } \\
\text { specific } \\
\text { methods or } \\
\text { technologies }\end{array}$ & $\begin{array}{l}\text { - Immersive, } \\
\text { i.e. inclusion } \\
\text { unconstrained }\end{array}$ & $\begin{array}{l}\text { - All actors are in } \\
\text { principle equal in } \\
\text { terms of } \\
\text { impacting not } \\
\text { only the co- } \\
\text { constructed } \\
\text { strategies but also }\end{array}$ & 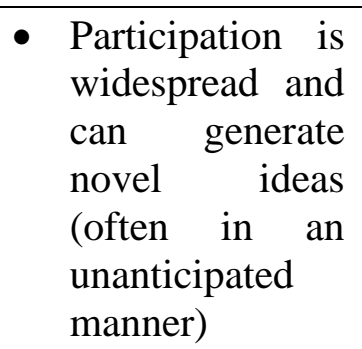 & $\begin{array}{l}\text { - Organization of } \\
\text { "extreme inclusion" } \\
\text { is challenging for } \\
\text { organizations, } \\
\text { including a risk of } \\
\text { "anarchy" } \\
\text { - Full equality cannot }\end{array}$ \\
\hline
\end{tabular}




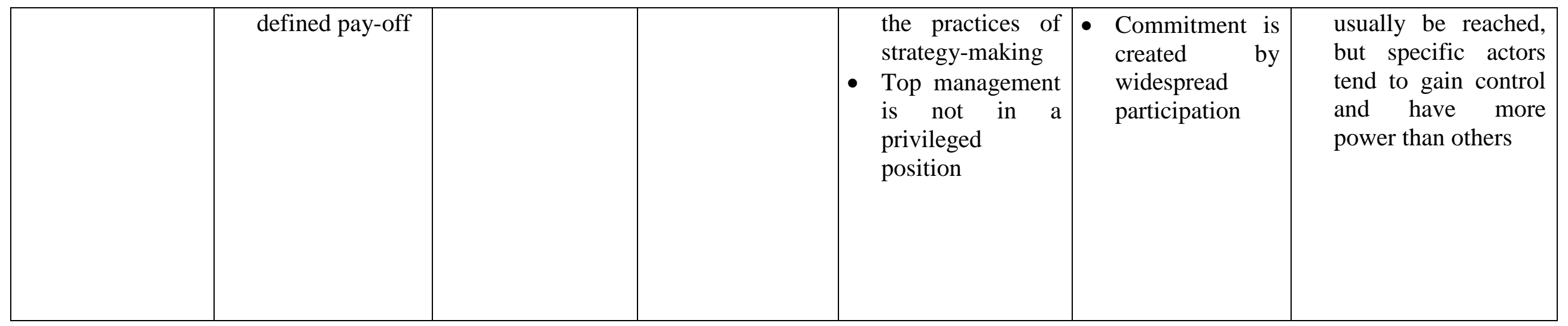

Table Three perspectives on participation and open strategy 